ARTICLE

Received 31 Oct 2014 | Accepted 18 Mar 2015 | Published 24 Apr 2015

DOI: $10.1038 /$ ncomms7947 OPEN

\title{
Deoxynybomycins inhibit mutant DNA gyrase and rescue mice infected with fluoroquinolone-resistant bacteria
}

Elizabeth I. Parkinson ${ }^{1}$, Joseph S. Bair ${ }^{1}$, Bradley A. Nakamura ${ }^{1}$, Hyang Y. Lee ${ }^{1}$, Hani I. Kuttab ${ }^{1}$, Emma H. Southgate ${ }^{1}$, Stéphane Lezmi ${ }^{2}$, Gee W. Lau ${ }^{2} \&$ Paul J. Hergenrother ${ }^{1}$

Fluoroquinolones are one of the most commonly prescribed classes of antibiotics, but fluoroquinolone resistance (FQR) is widespread and increasing. Deoxynybomycin (DNM) is a natural-product antibiotic with an unusual mechanism of action, inhibiting the mutant DNA gyrase that confers FQR. Unfortunately, isolation of DNM is difficult and DNM is insoluble in aqueous solutions, making it a poor candidate for development. Here we describe a facile chemical route to produce DNM and its derivatives. These compounds possess excellent activity against FQR methicillin-resistant Staphylococcus aureus and vancomycin-resistant Enterococci clinical isolates and inhibit mutant DNA gyrase in-vitro. Bacteria that develop resistance to DNM are re-sensitized to fluoroquinolones, suggesting that resistance that emerges to DNM would be treatable. Using a DNM derivative, the first in-vivo efficacy of the nybomycin class is demonstrated in a mouse infection model. Overall, the data presented suggest the promise of DNM derivatives for the treatment of FQR infections.

\footnotetext{
${ }^{1}$ Roger Adams Laboratory, Department of Chemistry, University of Illinois at Urbana-Champaign, 600 South Mathews Avenue, Urbana, Illinois 61801, USA ${ }^{2}$ College of Veterinary Medicine, Veterinary Medicine Basic Sciences Building, University of Illinois at Urbana-Champaign, 2001 South Lincoln Avenue, Urbana, Illinois 61802, USA. Correspondence and requests for materials should be addressed to P.J.H. (email: hergenro@illinois.edu).
} 
F luoroquinolones (FQs) were introduced into the clinic in the early 1980s and since then have become one of the most widely prescribed classes of antibiotics ${ }^{1-3}$. Although early FQs were primarily used to treat Gram-negative infections, later generation FQs were also commonly employed against infections caused by Gram-positive pathogens 1,4 . FQs are prescribed for severe or antibiotic-resistant urinary tract infections, respiratory tract infections $s^{2,4}$, gonoccocal infections, tuberculosis and as a prophylactic for anthrax ${ }^{5}$. FQs act by inhibiting bacterial type IIA topoisomerases, specifically DNA gyrase (composed of GyrA and $\mathrm{B}$ subunits) and topoisomerase IV (composed of ParC and E subunits). These enzymes catalyse the introduction of negative supercoils and the decatenation of interlinked chromosomes, respectively ${ }^{6-8}$.

Although FQs have demonstrated great utility in the clinic, their widespread use has resulted in significant resistance ${ }^{4}$. Nearly all vancomycin-resistant enterococcus (VRE) and methicillinresistant $S$. aureus (MRSA) are also resistant to $\mathrm{FQs} s^{9}$; thus, $\mathrm{FQs}$ can no longer be used to treat such infections. FQs are commonly prescribed for Neiserria gonorrhoeae and Pseudomonas aeruginosa infections, but $\mathrm{FQ}$ resistance (FQR) is now observed in a substantial fraction of these isolates, necessitating other treatments ${ }^{10}$. Target-site mutation is the major contributor to $\mathrm{FQR}^{1,4}$, with high-level resistance observed in bacteria possessing key mutations in both GyrA and ParC ${ }^{4}$. VRE and MRSA both harbour these target-site mutations, with point mutations in the quinolone resistance-determining region (QRDR) of the GyrA subunit of DNA gyrase and the ParC subunit of topoisomerase IV. These mutations alter residues important for the binding of FQs, resulting in an approximately tenfold decrease in binding affinity $^{11,12}$. Nearly $100 \%$ of MRSA substitute Ser84 of GyrA with Leu ${ }^{13-21}$. Similarly, nearly all FQR VRE substitute Ser83 of GyrA with Ile, Arg or Tyr $22-26$.

Nybomycin (NM) is a natural product first identified from a culture of a streptomycete isolated from a Missouri soil sample and found to have antibacterial activity 27,28 . During efforts to determine its structure, Rinehart and Renfroe ${ }^{29}$ synthesized a related compound, deoxynybomycin (DNM, Fig. 1a), which was later found to be a natural product and to have more potent activity than NM against a range of bacteria ${ }^{29,30}$. More recently, DNM was found to have activity against FQR MRSA with the S84L mutation in GyrA of DNA gyrase ${ }^{15}$. However, isolation of NM and DNM from natural sources is non-trivial ${ }^{31}$ and the only reported total synthesis of DNM is very low yielding ${ }^{32,33}$. In addition, the low solubility of DNM in any solvent other than concentrated acid presents challenges for its biological evaluation and limits its potential in-vivo.

Described herein is an efficient total synthesis of DNM and modifications of this route are used to construct the first DNM derivatives. DNM and several of the derivatives show outstanding antibacterial potency and selectivity against FQR MRSA and VRE clinical isolates. DNM and its derivatives inhibit the mutant DNA gyrase responsible for FQR and resistance to DNM and derivatives results in re-sensitization to FQs, suggesting a resistance cycling that could be useful in the clinic. Finally, using a DNM derivative with superior solubility and pharmacokinetic properties, the first in-vivo activity of this class of compounds is demonstrated.

\section{Results}

Total synthesis of DNM and construction of derivatives. Owing to the documented difficulty of isolating DNM from natural sources $^{31}$, we aimed to develop an efficient, modular and flexible synthesis of DNM that could also be used to construct derivatives. Previously, we reported a synthesis of the natural product a<smiles></smiles>
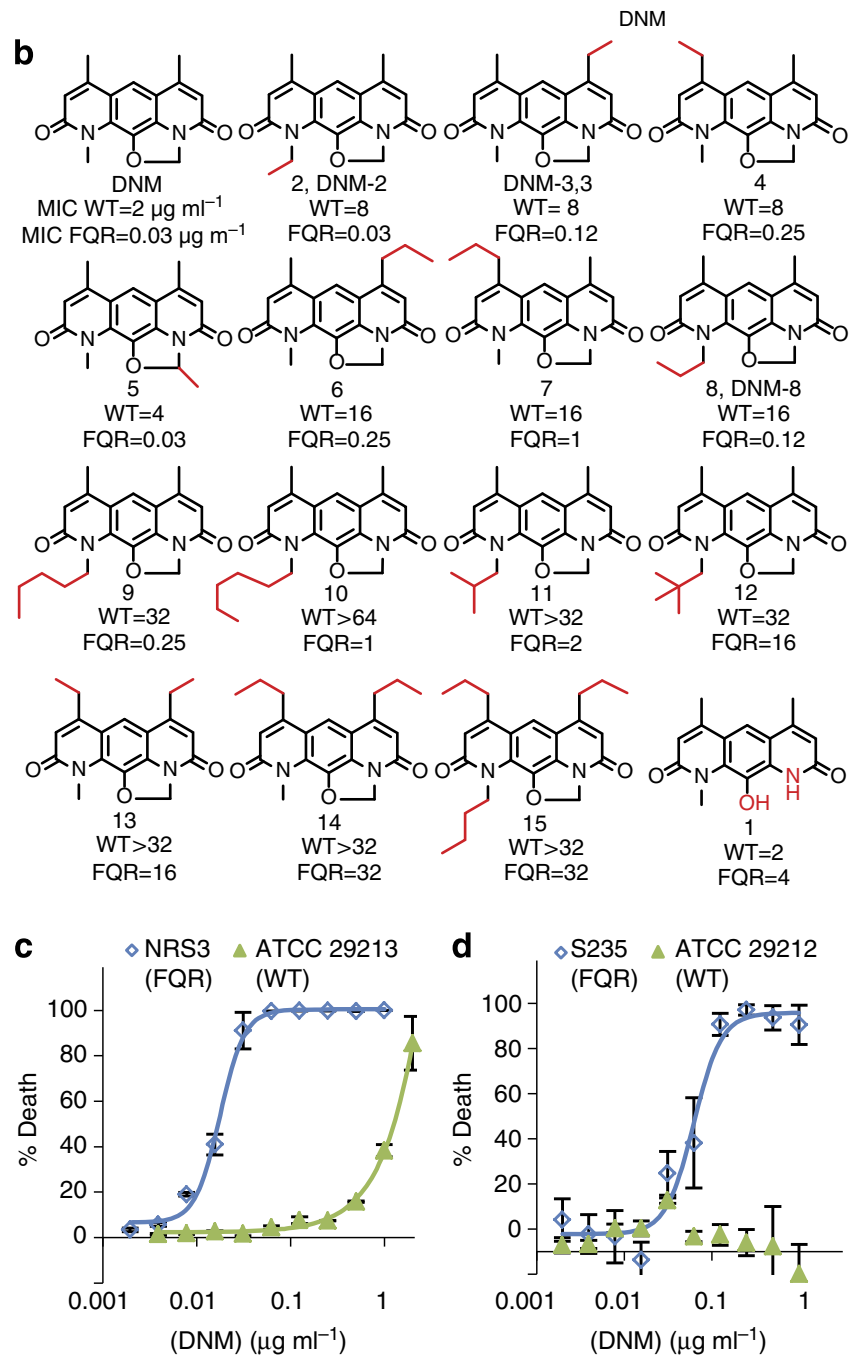

Figure 1 | Synthesis and antibacterial activity of DNM and derivatives. (a) Final step in the synthesis of DNM. The letters A, B, C and D around the structure of DNM denote sites of derivitization. (b) Structure of DNM and derivatives, and their activities against WT S. aureus (ATCC 29213, WT) and FQR S. aureus (NRS3, FQR). Activity is from three independent replicates of the microdilution broth assay and is reported as the MIC in $\mu \mathrm{g} \mathrm{ml}^{-1}$. (c) Dose-response curves for FQS S. aureus (ATCC 29213) and FQR S. aureus (NRS3) treated with DNM. Data shown are from three independent replicates \pm s.e.m. (d) Dose-response curves for FQS Enterococcus (ATCC 29212) and FQR Enterococcus (S235) treated with DNM. Data shown are from three independent replicates \pm s.e.m.

deoxynyboquinone (DNQ) that relies on a mixed Suzuki crosscoupling followed by a palladium-catalysed ring closing and deprotection to give diazaanthracenol 1 (Fig. 1a) (34 $^{34}$. To construct $\mathrm{DNQ}, \mathbf{1}$ is oxidized to give the desired quinone ${ }^{34}$. We found that 1 could be converted to DNM in a single step by insertion of the methylene bridge in a reaction inspired by Rinehart's degradation studies and by bridge insertions in similar systems $s^{32,33,35}$. Reaction of $\mathbf{1}$ with dibromomethane gave DNM in a 73\% yield (Fig. 1a). Through this route, DNM was obtained in seven steps 
with an overall yield of $11 \%$, an improvement over the only other reported total synthesis $(0.84 \% \text { overall yield })^{32,33}$.

This flexible synthetic route also allowed for rapid generation of a variety of derivatives that have not been found as natural products. We hypothesized that addition of alkyl chains would disrupt $\pi$-stacking between DNM molecules, thus increasing both aqueous and organic solubility, similar to what was observed with DNQ derivatives ${ }^{36}$. By changing the iodoamides used in the Suzuki cross-coupling (see General protocol A in Supplementary Methods), three compounds were synthesized that substituted ethyl for methyl at positions $A, B$ and $C$ (compounds 2, 3, and $\mathbf{4}$, respectively, Fig. 1b). The derivative with a methyl substitution at $D$ was generated by using 1,1-dibromoethane in place of dibromomethane in the final step, to provide compound $\mathbf{5}$ (Fig. 1b). Other compounds with single sites of derivatization (6-12) and multiple sites of derivatization (13-15) were also constructed. Full synthetic routes along with experimental details and characterization data can be found in the Supplementary Methods. Compounds with small alkyl appendages have markedly improved solubility (3- to 13-fold) in $\mathrm{pH} 7.4$ PBS relative to DNM (Supplementary Table 1) and all compounds synthesized have improved dimethyl sulfoxide (DMSO) solubility compared with the parent compound (Supplementary Table 1).

Evaluation of DNM and derivatives against FQR MRSA and VRE. DNM was evaluated against both FQ-sensitive $S$. aureus (ATCC 29213) and FQR MRSA (NRS3, which has GyrA S84L and ParC S80F). DNM showed modest activity against the FQ-sensitive (FQS) strain 29213. However, DNM showed excellent activity against the FQR NRS3 (Minimum Inhibitory Concentration, MIC $=0.03 \mu \mathrm{g} \mathrm{ml}^{-1}$, Fig $\left.1 \mathrm{~b}, \mathrm{c}\right)$. This MIC compares favourably with standard-of-care treatments for Gram-positive infections including vancomycin (MIC for NRS3 $=8 \mu \mathrm{g} \mathrm{ml}^{-1}$ ), daptomycin (MIC for NRS3 $=8 \mu \mathrm{g} \mathrm{ml}^{-1}$ ) and linezolid (MIC for NRS3 $=0.5$ $\left.\mu \mathrm{g} \mathrm{ml}^{-1}\right)$. The sensitivity of FQR VRE was also explored. DNM had no detectable activity against FQS Enterococcus (ATCC 29212, MIC $>1.0 \mu \mathrm{g} \mathrm{ml}^{-1}$ ), but it potently inhibited the growth of FQR VRE (clinical isolate S235, which has GyrA S83I and ParC S80I, $\mathrm{MIC}=0.125 \mu \mathrm{g} \mathrm{ml}^{-1}$, Fig. 1d). DNM was also evaluated against a panel of Gram-negative bacteria (Supplementary Table 2). It showed no detectable activity against wild-type (WT) or FQR $P$. aeruginosa or Acinetobacter baumannii. Moderate activity was seen with a DNM derivative against a permeabilized strain of Escherichia coli, suggesting that DNM and its derivatives are unable to penetrate Gram-negative bacteria.

DNM derivatives were evaluated against both FQS S. aureus (ATCC 29213) and FQR MRSA (NRS3), and their MIC values are listed in Fig. 1b. Similar to DNM, most derivatives showed significantly enhanced activity against FQR NRS3 compared with FQS 29213. In general, compounds with a single methyl addition retained good activity against NRS3 (2-5). Further substitution at $B$ was relatively well tolerated (6), while substitution at $C$ was generally less well tolerated (7). Compounds possessing longer chains at $A$ generally retained potency $(\mathbf{8}-\mathbf{1 0})$. However, compounds with bulky substitutions at $A$ (11-12), multiple substitutions (13-15), or without the methylene bridge (1) were markedly less active.

Activity of DNM or derivatives against FQR clinical isolates. DNM and two of the most potent derivatives (DNM-2 and DNM-8) were evaluated against a panel of MRSA and VRE clinical isolates (Figs 2a,b). As shown in Fig. 2, all MRSA and VRE strains were sensitive to these compounds and resistant to ciprofloxacin (CIP). To understand this selectivity, the QRDRs of GyrA and ParC for many of these isolates were sequenced
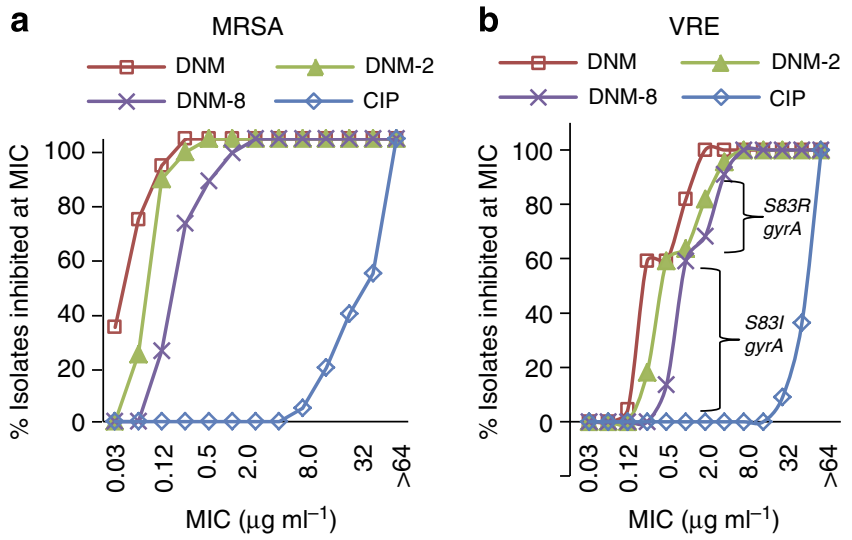

Figure 2 | Sensitivity of MRSA and VRE clinical isolates to DNM, DNM-2, DNM-8 and CIP. (a) The percentage of MRSA clinical isolates $(n=21)$ with an MIC at or lower than the concentration shown. (b) The percentage of VRE clinical isolates $(n=22)$ with an MIC at or lower than the concentration shown.

(Supplementary Tables 3 and 4). Although different substitution patterns were found for MRSA ParC, all sequenced strains have the same mutation in GyrA (S84L), consistent with the notion that this mutation sensitizes bacteria to DNM. Similar to the MRSA isolates, the VRE isolates have many different substitutions in ParC, which do not appear to correlate with sensitivity. Unlike the MRSA isolates, the majority of VRE isolates have two different substitutions for GyrA (S83I or S83R). The sensitivity of these strains is affected by this substitution with VRE harbouring the S83I mutation being very sensitive to DNM (MIC $=0.125-$ $1 \mu \mathrm{g} \mathrm{ml}^{-1}$ ) and those with the S83R mutation being less sensitive (MIC $\geq 1 \mu \mathrm{g} \mathrm{ml}^{-1}$ ). The activity of the DNM-2 and DNM-8 against these panels of clinical isolates closely mirrors that of DNM (Fig. 2a,b). Full details of the sensitivity of each strain can be found in Supplementary Tables 3 and 4.

Inhibition of mutant DNA gyrase by DNM and derivatives. To further investigate the importance of the GyrA mutation for DNM activity, the ability of DNM, DNM-2 and CIP to inhibit DNA gyrase was determined by using an in-vitro DNA cleavage assay. In this assay, DNA gyrase is coincubated with supercoiled DNA and the compound of interest. Inhibition at the cleavage complex of DNA gyrase leads to an increase in either doubly nicked linear (L) DNA (for example, inhibition by $\mathrm{CIP}^{37}$ ) or singly nicked open circular (OC) DNA (for example, inhibition by GSK299423 (ref. 38)). GSK299423 is a recently discovered DNA gyrase inhibitor that is hypothesized to stabilize the DNA-enzyme complex, either pre-cleavage or after the formation of a single-strand break resulting in a buildup of OC $\mathrm{DNA}^{38}$. Similar to previous studies, we found that CIP potently inhibits WT DNA gyrase with a greater than sevenfold increase in L DNA being observed at concentrations as low as $0.68 \mu \mathrm{M}$ (Fig. 3a, full gels in Supplementary Fig. 1, quantification in Supplementary Fig. 2). In addition, in a time-course assay, inhibition of WT DNA gyrase by CIP resulted in a timedependent buildup of L DNA (Fig. 3b, full gels in Supplementary Fig. 3). Alternatively, when either DNM or DNM-2 was incubated with WT DNA gyrase, neither showed similar increases in L or OC DNA, suggesting that these compounds are poor inhibitors of WT DNA gyrase (Fig. 3a). In addition, during the time-course study with these compounds, buildup of $\mathrm{L}$ DNA was only observed at later time points and to a smaller degree (Fig. 3b and Supplementary Fig. 2). 
a
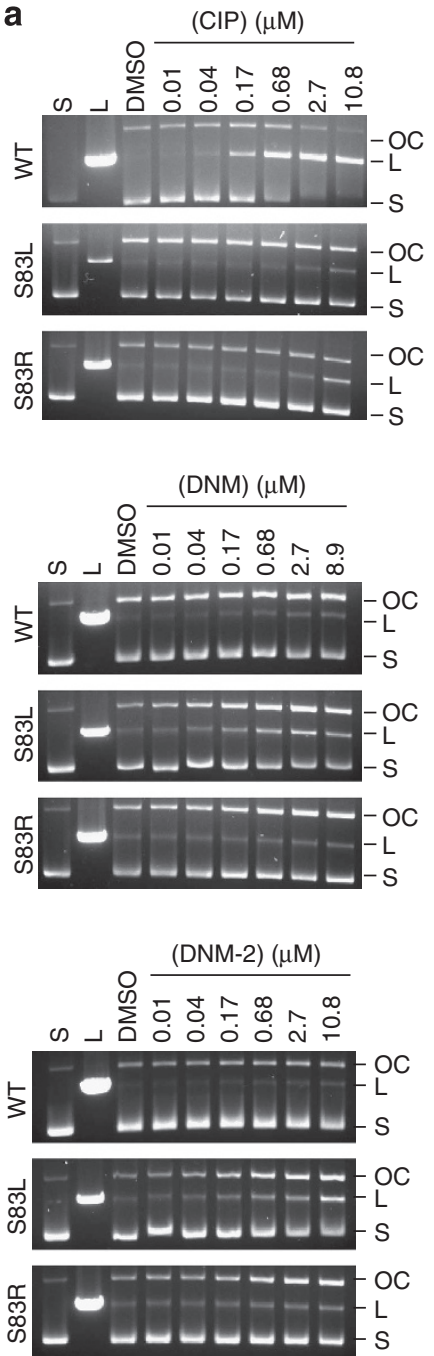
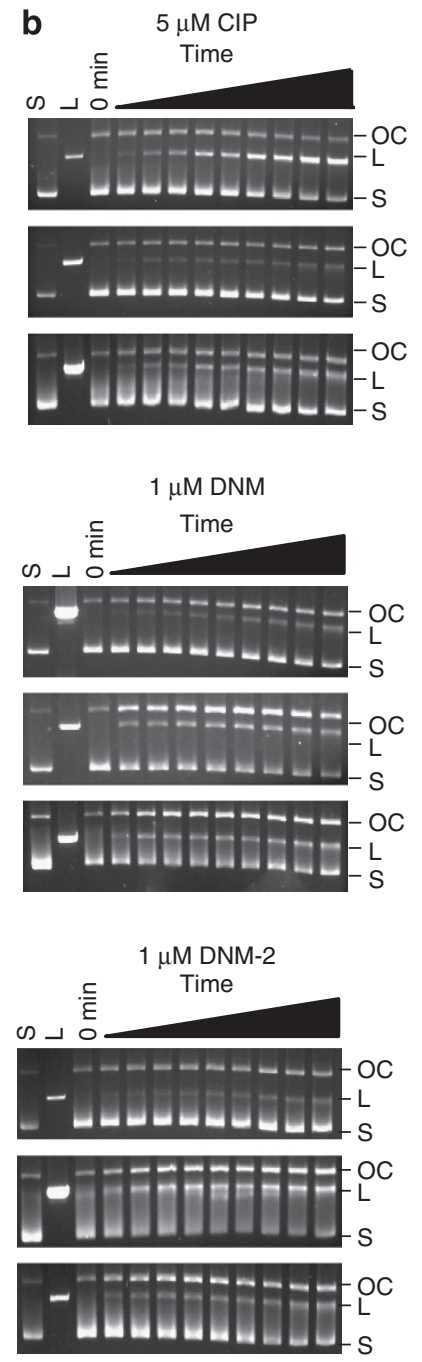

Figure 3 | Inhibition of WT and mutant DNA gyrase. (a) DNA cleavage assay with WT, S83L and S83R E. coli DNA gyrase in the presence of increasing concentrations of CIP, DNM and DNM-2. Concentrations were $0.01,0.04,0.017,0.68,2.7$ and $10.8 \mu \mathrm{M}$, except for DNM, which was $8.9 \mu \mathrm{M}$ for the highest concentration. S, supercoiled; L, linear; OC, open circular or nicked DNA. (b) Time course of DNA cleavage with WT, S83L and S83R E. coli DNA gyrase in the presence of $5 \mu \mathrm{M} \mathrm{CIP}, 1 \mu \mathrm{M}$ DNM and $1 \mu \mathrm{M}$ DNM-2. Time points were 0, 1, 3, 5, 10, 15, 20, 30,60 and $90 \mathrm{~min}$. All gels are representative data from at least three independent experiments.

The ability of CIP, DNM and DNM-2 to inhibit S83L or S83R DNA gyrase was then determined. CIP was much less effective at inhibiting either S83L or S83R DNA gyrase compared with WT, with only small increases in L DNA being observed (Fig. 3a). In addition, minimal change was observed with $5 \mu \mathrm{M}$ CIP at up to $1.5 \mathrm{~h}$ (Fig. 3b). Time-course studies performed with an increased concentration of CIP $(200 \mu \mathrm{M})$ and S83L DNA gyrase revealed a similar pattern of inhibition to that of WT DNA gyrase, suggesting that the residual inhibition goes through a similar mechanism (Supplementary Fig. 4a). DNM and DNM-2 induce only small increases in L DNA with S83L DNA gyrase (Fig. 3a). Instead, DNM inhibition of S83L DNA gyrase led to a significant buildup of OC DNA at $0.17 \mu \mathrm{M}(P<0.05)$, with a similar increase observed for DNM-2 (Fig. 3a and Supplementary Fig. 2). This buildup does not diminish over time (Fig. 3b), suggestive of a mode of inhibition more similar to GSK 299423 than to CIP. Increasing concentrations of DNM-2 to $200 \mu \mathrm{M}$ and increasing the time up to $2 \mathrm{~h}$ confirmed that this OC buildup is not a fleeting event as occurs with CIP (Supplementary Fig. 4b). DNM or DNM-2 inhibition of S83R also led to a buildup of OC DNA similar to that seen with S83L DNA gyrase only at a slightly higher concentration or longer time points, consistent with the activity of these compounds against VRE with the S83R DNA gyrase. Overall, these results are consistent with the clinical isolate data, supporting the critical importance of a mutant DNA gyrase for sensitizing bacteria to DNM. Finally, to determine the selectivity of DNM and derivatives for bacterial DNA gyrase, a decatenation assay with human topoisomerase II was performed. Although doxorubicin inhibited human topoisomerase II at concentrations as low as $3 \mu \mathrm{M}$, DNM-2 showed no significant inhibition at concentrations up to $30 \mu \mathrm{M}$ (Supplementary Fig. 5).

Development of resistance to DNM. To explore the development of resistance to both CIP and DNM in S. aureus, resistant strains of ATCC 29213 were generated. Consistent with previous reports $^{39,40}$, high-level resistance to CIP was generally not achieved in a single step. Instead, low-level resistance (CIP $\mathrm{MIC}=4-8 \mu \mathrm{g} \mathrm{ml}^{-1}$ ) was usually achieved with the first step and corresponded to a mutation in ParC (for example, E84K or S80F; Fig. 4a and Supplementary Fig. 6). Unsurprisingly, these low-level resistant strains that do not have the S84L mutation in GyrA were not sensitive to DNM or DNM-2. Development of high-level CIP resistance (CIP MIC $=16-64 \mu \mathrm{g} \mathrm{ml}^{-1}$ ) similar to what is often seen in clinical isolates ${ }^{13,15,17}$ was observed at the second step and corresponded to an S84L mutation in GyrA. These high-level CIP-resistant strains were extremely sensitive to DNM $\left(\mathrm{MIC}=0.03-0.06 \mu \mathrm{g} \mathrm{ml}^{-1}\right)$ and DNM-2 $(\mathrm{MIC}=0.06-$ $\left.0.12 \mu \mathrm{g} \mathrm{ml}^{-1}\right)$. These FQR bacteria were then exposed to DNM in an effort to create DNM-resistant isolates. The development of DNM resistance in high-level CIP-resistant strains was a rare event, with resistance frequencies ranging from $1 \times 10^{-10}$ to $7 \times 10^{-10}$ (Supplementary Fig. 6). When these strains were found, they showed dramatically improved sensitivity to CIP $\left(\mathrm{MIC}=0.25-8.0 \mu \mathrm{g} \mathrm{ml}^{-1}\right)$. All these strains had reverted to WT GyrA (Ser84), with the more CIP-sensitive strains also having WT ParC and the less CIP-sensitive strains retaining ParC mutations (Supplementary Fig. 6). This complete cycle of complementary resistance/sensitivity of CIP and DNM is shown in Fig. 4a and the complete list of resistant strains generated and the sequences of their QRDR is shown in Supplementary Fig. 6.

Resistance development on co-treatment with CIP and DNM-2 was then explored (Supplementary Fig. 7). A low-level CIP-resistant strain (29213-C1) was used in these studies. On treatment with either CIP or DNM-2, resistant colonies were observed. However, no colonies were observed on co-treatment (resistance frequency $<1.0 \times 10^{-10}$ ).

In-vivo efficacy of DNM-2. As a prelude to exploring in-vivo efficacy, the toxicity and pharmacokinetic profile of DNM and key derivatives was evaluated. Treatment of red blood cells (RBCs) with DNM and key derivatives indicated that none of these compounds induce haemolysis (Supplementary Fig. 8a). In addition, DNM-2 demonstrated no significant DNA intercalation at concentrations up to $30 \mu \mathrm{M}$ (Supplementary Fig. 8b). This data combined with previously published data showing that DNM is non-toxic to normal (that is, non-cancerous) cell lines ${ }^{41}$ suggests that these compounds would probably be well tolerated in-vivo. Treatment of mice with increasing concentrations of DNM, DNM-2 and DNM-3 showed that all three compounds were well tolerated up to the highest dose evaluated $\left(50 \mathrm{mg} \mathrm{kg}^{-1}\right.$ by oral gavage). Pharmacokinetic studies were next performed on DNM, DNM-2 and DNM-3. Although DNM itself showed very low 

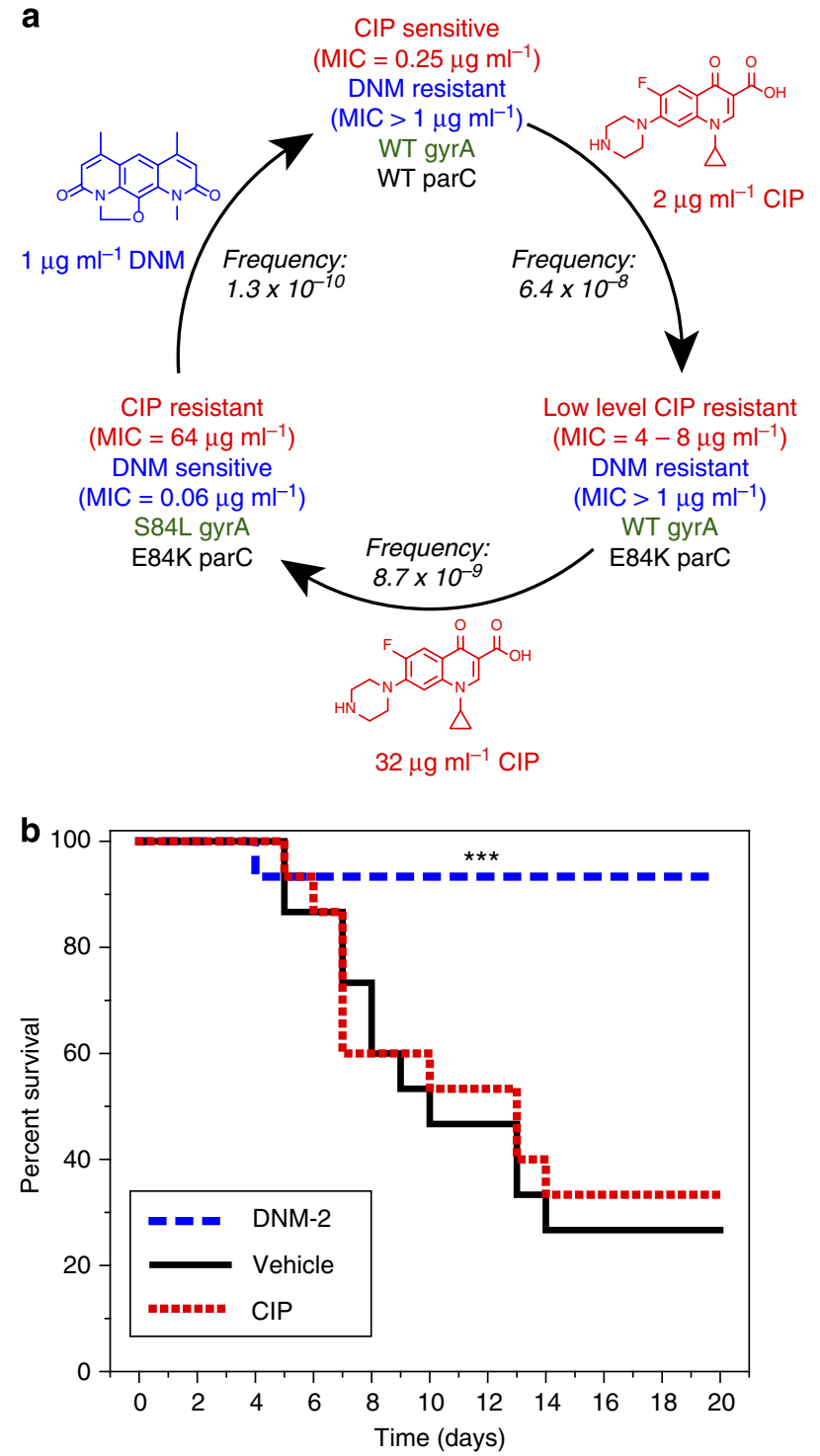

Figure 4 | Resistance mechanisms and in-vivo activity. (a) Representative data of the resistance cycle observed when bacteria are sequentially treated with CIP then DNM. Each strain generated is listed with the MIC of CIP (red), DNM (blue), as well as mutation status of the QRDR of GyrA (green) and $\operatorname{ParC}$ (black) shown below. The selection pressure used in each step is shown over the arrow along with the mutation frequency. (b) Kaplan-Meier curves showing the survival rates of mice infected with MRSA (NRS3, FQR). The mice received vehicle alone, $50 \mathrm{mg} \mathrm{kg}^{-1} \mathrm{CIP}$, or $50 \mathrm{mg} \mathrm{kg}^{-1} \mathrm{DNM}-2$ by oral gavage once daily for 10 days; $n=15$ for each group. ${ }^{\star \star \star} P<0.005$ versus vehicle and $\mathrm{CIP}$, log rank survival test.

serum exposure $\left(C_{\max }<0.20 \mu \mathrm{M}\right.$ or $\left.0.060 \mu \mathrm{g} \mathrm{ml}^{-1}\right)$ after a $50-\mathrm{mg} \mathrm{kg}^{-1}$ oral dose, DNM-2 showed good bioavailability with a peak serum concentration of $42.6 \mu \mathrm{M}\left(12.8 \mu \mathrm{g} \mathrm{ml}^{-1}\right)$ and an area under the curve of $44 \mathrm{~h} \mu \mathrm{g} \mathrm{ml}^{-1}$ (Supplementary Fig. 9 and Supplementary Table 5). DNM-3 showed an intermediate level of bioavailability with a peak serum concentration of $4.3 \mu \mathrm{M}\left(1.26 \mu \mathrm{g} \mathrm{ml}^{-1}\right)$ and an area under the curve of $4 \mathrm{~h} \mu \mathrm{g} \mathrm{ml}^{-1}$. The bioavailability of these compounds mirrors the aqueous solubility, suggesting that at least for this limited set of compounds aqueous solubility could be a reasonable predictor of oral bioavailability.

To explore the effect of sustained treatments in-vivo, DNM-2 was administered to mice once daily for 10 days (via oral gavage at $50 \mathrm{mg} \mathrm{kg}^{-1}$ ) and markers of haematological and non-haematological toxicity were examined. No clinically significant evidence for myelosuppression, renal injury or hepatic toxicity was identified (Supplementary Table 6). Kidney, brain, lung, liver, spleen, heart, and stomach sample examinations also did not reveal any evidence of toxicity. In small intestine sections, mild intestinal dilation associated with villi atrophy were noted (Supplementary Fig. 10). Increased vacuolation of white and brown adipocytes with a minimal increase in triglyceride levels were noted as well. These changes were probably indirectly related to the drug and possibly due to the antibiotic effects on the intestinal flora. As none of the mice showed any clinical symptoms, these changes were considered of minimal significance. With this indication that DNM-2 offered good exposure on oral dosing with no observable toxicity, an in-vivo model of mouse sepsis was conducted. Mice were infected with FQR MRSA (NRS3) via tail vein injection. Mice were treated with CIP (50 $\mathrm{mg} \mathrm{kg}^{-1}$, oral gavage), DNM-2 (50 $\mathrm{mg} \mathrm{kg}^{-1}$, oral gavage) or vehicle control once daily for 10 days. As shown by the KaplanMeier survival curve in Fig. 4b, mice treated with DNM-2 showed a significant survival difference relative to both CIP and vehicletreated control $(P<0.005$, Fig. $4 \mathrm{~b})$.

\section{Discussion}

Using a synthetic route building on a palladium-catalysed mixed cross-coupling and a methylene bridge insertion, hundreds of milligrams of the natural-product DNM were prepared as described herein. The modular nature of the synthesis also allows access to non-natural DNM derivatives, many of which display similar antibacterial efficacy but with significantly better solubility properties than the parent. Specifically, small alkyl appendages greatly improve aqueous solubility: DNM has aqueous solubility of only $9 \mu \mathrm{M}$ compared with $121 \mu \mathrm{M}$ for DNM-2. This improved solubility is probably because of the ability of the short alkyl chains to break up $\pi$-stacking similar to what was observed with derivatives of $\mathrm{DNQ}^{36,42}$. Longer or more alkyl chains do not display similar increases in aqueous solubility probably because of the increased hydrophobicity of these compounds. With these compounds in hand, a structure-activity relationship was established and derivatives were found to have comparable potencies to the parent against FQR MRSA and VRE in cell culture and against mutated DNA gyrase in-vitro.

The major mechanism of $\mathrm{FQR}$ for bacteria involves the mutation of FQ targets DNA gyrase and topoisomerase IV. Although nearly all FQR bacteria found to date have such mutations, the exact mutation can vary based on the bacterium. For MRSA, nearly $100 \%$ have the S84L mutation in DNA gyrase 13-21. Similarly, Bacillus anthracis, E. coli and A. baumannii also have the analogous serine mutated to leucine ${ }^{43-45}$. In VRE the serine is mutated to multiple different residues (Ile, Arg and Tyr), while in Streptococcus pneumoniae, Klebsiella pneumonia and $N$. gonorrhoeae this Ser is often changed to either Phe or $\mathrm{Tyr}^{22-26,46-48}$. P. aeruginosa differs in that it naturally has a Thr instead of the Ser. However, $P$. aeruginosa is similar to VRE in that the Thr is mutated to an Ile in FQR strains. We now show that DNM has excellent activity versus Ser $\rightarrow$ Leu or Ser $\rightarrow$ Ile mutants with moderate activity in Ser $\rightarrow$ Arg strains, with these cell culture results correlating with the potencies of the compounds in in-vitro assays with DNA gyrase and mutants. The ability of DNM to target these different mutants suggests that this natural product or its derivatives could be broadly applicable against $\mathrm{FQR}$ bacteria regardless of the exact nature of the Ser mutation.

FQs inhibit DNA gyrase causing double-stranded breaks that appear as a buildup of L DNA in a DNA gyrase cleavage assay (Fig. 3 and ref. 37). Kampranis and Maxwell ${ }^{37}$ have demonstrated 
that FQs initially stabilize a single phosphotyrosine bond as evidenced by an initial buildup of OC DNA, also observed in Fig. 3b. However, the FQ stabilization of a single-strand break causes an even faster second cleavage event that is also stabilized by FQs, thus explaining the rapid buildup of linear $\mathrm{DNA}^{37}$. Another DNA gyrase inhibitor, GSK299423, acts via a different mechanism ${ }^{38}$. Unlike FQs that bind within the two active sites, it binds between the active sites stabilizing either an uncleaved or a single-stranded cleaved DNA. The stabilization induced by GSK299423 differs from that of CIP in that it does not result in a second cleavage event and instead causes a buildup of OC DNA. The more potent activity of DNM against FQR-mutant DNA gyrase suggests that DNM probably binds similarly to FQs, near the mutated residues and thus near the two active sites. Despite this similarity in binding position, the phenotype of DNM in the DNA cleavage assay (that is, the buildup of OC DNA) suggests that its overall mode of inhibition is more similar to that of GSK299423. The mutational status of ParC does not affect sensitivity to DNM, as shown by the data from the clinical isolates and resistance mutants.

In this study, we showed that an entire resistance/sensitization cycle is possible beginning with S. aureus (ATCC 29213) that is FQS/DNM resistant. After multiple rounds of selection against CIP, a FQR/DNM-sensitive strain was generated. Next, after a selection round with DNM, a FQS/DNM-resistant strain was found. These results suggest intriguing clinical possibilities for DNM, either alone or in combination with FQs. As surveillance data show the ubiquity of FQR in MRSA and VRE, a DNM compound could be an outstanding therapeutic option for these infections; indeed, a new orally available treatment for MRSA and VRE is a well-recognized clinical need ${ }^{49}$ and would be a welcome addition to the antibiotic arsenal. As resistance to DNM emerges, the data predict that such bacteria would be sensitive to FQs. At this point, a diagnostic test could be used to choose between FQ or DNM, or a co-treatment with both a FQ and DNM would be possible. As reported herein, co-resistance was not generated in cell culture, with no colonies being observed on treatment with $4 \mu \mathrm{g} \mathrm{ml}^{-1} \mathrm{CIP}$ and $6 \mu \mathrm{g} \mathrm{ml}^{-1} \mathrm{DNM}-2$.

Before this study, little to no data existed about the administration of DNM to animals. However, a related but less potent compound $\mathrm{NM}\left(\mathrm{C}=\mathrm{CH}_{2} \mathrm{OH}\right)$ has been examined in mice. It was found to be well tolerated when dosed either subcutaneously, orally or by intraperitoneal injection ${ }^{27}$. However, it showed no activity in mice infected with various bacteria (K. pneuomoniae, S. aureus or Mycobacterium tuberculosis), leading Brock and Sokolski ${ }^{27}$ to suggest that this high tolerability and lack of efficacy is probably a result of the very poor solubility of NM (similar to DNM, it is only soluble in concentrated acid) and thus lack of absorption. We demonstrated that DNM also has a high maximal tolerated dose ( $>50 \mathrm{mg} \mathrm{kg}^{-1}$ oral gavage), but pharmacokinetic analysis indicate that it is not absorbed to any appreciable degree. However, DNM-2, which has improved solubility, was also very well tolerated (maximal tolerated dose $>50 \mathrm{mg} \mathrm{kg}^{-1}$ ) and showed favourable pharmacokinetic properties when dosed orally. In addition, in this study we found that orally administered DNM-2 is effective in treating mice infected with MRSA, thus showing the first in-vivo efficacy for this class of compounds.

FQR pathogens are now a significant medical problem and the data presented herein reveal the considerable translational potential of DNM derivatives, including the following: (1) a short and efficient synthetic route has been developed that can readily supply large amounts of compound. (2) DNM-2 has outstanding pharmacokinetic $(\mathrm{PK})$ properties with a peak serum concentration $\left(\sim 50 \mu \mathrm{M}\right.$ when given at $50 \mathrm{mg} \mathrm{kg}^{-1}$ orally) far exceeding the MIC. (3) DNM-2 is extremely well tolerated in mice, with no signs of toxicity at the dose levels tested. This is consistent with our data showing these compounds do not induce haemolysis or inhibit human topoisomerase II. (4) DNM-2, when given orally, has outstanding efficacy in a mouse model of MRSA infection. An oral drug for MRSA and VRE is a well-recognized clinical need and DNM-2 has tremendous promise in this regard. (5) Finally, resistance to DNM is much more difficult than resistance to CIP, as shown by the resistance frequencies in Fig. 4a. A problem with novel antibacterials is that bacterial resistance typically necessitates the development of a new drug to treat those drug-resistant pathogens. However, when the inevitable resistance to $\mathrm{DNM} /$ derivatives does arise clinically, these bacteria will be sensitive to FQs, a widely used and wellunderstood class of antibiotics.

\section{Methods}

Synthesis of DNM and derivatives. Synthesis of the diazaanthracenols of DNM and the derivatives and chemical characterizations are described in the Supplementary Methods. The NMR spectra are shown in Supplementary Note 1.

Aqueous solubility determination. Initially, a small amount of solid compound (generally $0.5-1.5 \mathrm{mg}$ ) was measured into a $1.7-\mathrm{ml}$ Eppendorf tube. PBS ( $\mathrm{pH} 7.4$ ) was added to give a maximum final concentration of $1 \mathrm{mg} \mathrm{ml}^{-1}$ of compound. The compound was vortexed for $\sim 30 \mathrm{~s}$ before being placed into a bath sonicator (Cole Parmer, ultrasonic cleaner) for $1 \mathrm{~h}$. Longer incubation times (up to $24 \mathrm{~h}$ ) were performed with select compounds and no difference in solubility was observed; thus, $1 \mathrm{~h}$ was used for all subsequent testing. The tubes were vortexed again for $30 \mathrm{~s}$ before being centrifuged at maximum speed $(13,000 \times g)$ for $10 \mathrm{~min}$. The supernatant was then filtered through a $0.22-\mu \mathrm{m}$ syringe filter (Millipore Millex MP). The filtrate was then analysed by liquid chromatography-mass spectrometry $(\lambda=254 \mathrm{~nm}$, electrospray ionization-time-of-flight in positive mode, Agilent Technologies 6230 TOF LC/MS). The filtrate was diluted 1:2 and 1:4 and all three samples $(1 \times, 0.5 \times$ and $0.25 \times)$ were analysed in triplicate. Three independent replicates of each compound were performed. A calibration curve for each compound was generated from 1 to $40 \mu \mathrm{M}$ by dissolving the compound in DMSO and making dilutions of the stock in DMSO. The calibration curve (measured by ultraviolet absorbance) was linear over this range. The concentration of the samples was calculated based on the calibration curves.

Bacterial strains. MRSA and $P$. aeruginosa isolates were from Cubist Pharmaceuticals (Lexington, MA). VRE isolates were from a previously published collection $^{50}$. E. coli strains were obtained either from ATCC or Professor Cari Vanderpool (UIUC). A. baumannii isolates were obtained from Dr John Quale ${ }^{51}$.

Antibiotic susceptibility tests. Susceptibility testing was performed in triplicate, using the microdilution broth method as outlined by the Clinical and Laboratory Standards Institute ${ }^{52}$. Mueller Hinton $(\mathrm{MH})$ broth was used.

DNA amplification and sequencing analysis. A single colony of $S$. aureus grown on $\mathrm{MH}$ agar or a single colony of Enterococcus grown on Brain-Heart Infusion (BHI) agar was suspended in $50 \mu \mathrm{l}$ of the PCR mixture containing the primers (Supplementary Table 7) and PCR master mix (Platinum TaqDNA Polymerase, Invitrogen). PCR amplification was performed using an initial denaturation step of $94^{\circ} \mathrm{C}$ for $2 \mathrm{~min}$ followed by 35 cycles of $94^{\circ} \mathrm{C}$ for $30 \mathrm{~s}, 52^{\circ} \mathrm{C}$ (S. aureus. or Enterococcus faecalis) or $58^{\circ} \mathrm{C}$ (Enteroccocus faecium) for $30 \mathrm{~s}, 72^{\circ} \mathrm{C}$ for $50 \mathrm{~s}$. PCR products were purified further on a $1 \%$ agarose gel and DNA was extracted (QIAquick Gel Extraction Kit, Qiagen). DNA sequencing was performed by the W M. Keck Center for Comparative and Functional Genomics (UIUC). The NCBI standard nucleotide BLAST database was used to verify the identity of the PCR products and determine mutations within the sequences.

Site-directed mutagenesis. pTRCHisA-GyrA plasmid containing the gene for E. coli gyrase A was kindly provided by Professor David Hooper ${ }^{53}$. Primers for mutagenesis were designed using QuikChange Primer Design (Agilent) and their sequences can be found in Supplementary Table 7. Site-directed mutagenesis was carried out with the QuikChange Lightning Site-Directed Mutagenesis Kit (Agilent), according to the manufacturer's instructions, with the modification that NEB Turbo Competent E. coli were used as the host strain. All clones were confirmed by sequencing.

DNA gyrase expression. Expression of WT E. coli gyrase A and gyrase B was performed as previously described ${ }^{53}$. Briefly, pTRCHisA-GyrA, pTRCHisAGyrAS83L, pTRCHisA-GyrAS83R, or pTRCHisA-GyrB were introduced into One Shot BL21 Star (DE3) (NEB) by chemical transformation. Transformed cells were 
selected for on an Luria-Bertani (LB) ampicillin plate. Single colonies from a fresh plate were inoculated into $50 \mathrm{ml}$ of LB with $50 \mu \mathrm{g} \mathrm{ml}^{-1}$ ampicillin and incubated aerobically at $37^{\circ} \mathrm{C}$ with shaking at 250 r.p.m. overnight $(14-16 \mathrm{~h})$. The overnight culture was then used to inoculate 1 litre LB with $50 \mu \mathrm{g} \mathrm{ml}^{-1}$ ampicillin. The culture was grown aerobically with shaking at 250 r.p.m. until $A_{600}$ reached $0.4-0.6$. Protein expression was induced with a final concentration of $0.5 \mathrm{mM}$ of IPTG (isopropyl- $\beta$-D-thiogalactoside) at $37^{\circ} \mathrm{C}$ with shaking at 250 r.p.m. for $4 \mathrm{~h}$. The culture was harvested by centrifugation at $5,000 \times g$ for $5 \mathrm{~min}$ at $4{ }^{\circ} \mathrm{C}$. Cell pellets were frozen at $-20^{\circ} \mathrm{C}$, thawed on ice for $30 \mathrm{~min}$ and resuspended in $\mathrm{TGN}_{150}$ (20 mM Tris-HCl pH 7.5, $10 \%$ glycerol, $150 \mathrm{mM} \mathrm{NaCl}$ ) with $0.5 \mathrm{mg} \mathrm{ml}^{-1}$ lysozyme with $2 \mu \mathrm{g} \mathrm{ml}^{-1}$ aprotinin, $1 \mu \mathrm{g} \mathrm{ml}^{-1}$ leupeptin, $1 \mu \mathrm{g} \mathrm{ml}^{-1}$ pepstatin $\mathrm{A}$ and $100 \mu \mathrm{M}$ phenylmethanesulfonylfluoride. Cells were lysed by sonication at $35 \%$ amplitude ( $10 \mathrm{~s}$ pulse with $30 \mathrm{~s}$ rest, 6 times). The lysate was cleared by centrifugation at $35,000 \times \mathrm{g}$ for $30 \mathrm{~min}$ at $4^{\circ} \mathrm{C}$. The supernatant was batch loaded onto $1 \mathrm{ml}$ of 1:1 Ni-NTA agarose (Qiagen) at $4{ }^{\circ} \mathrm{C}$ for $30 \mathrm{~min}$ with inversion. The resin was washed with $20 \mathrm{ml} \mathrm{TGN}{ }_{150}$ with $10 \mathrm{mM}$ imidazole followed by $10 \mathrm{ml}$ of wash buffer (20 mM Tris-HCl pH 7.5, 10\% glycerol, $300 \mathrm{mM} \mathrm{NaCl}, 10 \mathrm{mM}$ imidazole) and eluted with $\mathrm{TGN}_{150}$ containing imidazole concentrations of $25,50,100,200,300$ and $500 \mathrm{mM}$. Eluted fractions were assessed by SDS-PAGE, using 4-20\% TGX Mini-PROTEAN gels (Bio-Rad). Fractions containing pure protein were pooled and dialysed against TDEN buffer ( $50 \mathrm{mM}$ Tris- $\mathrm{HCl} \mathrm{pH} 7.5,5 \mathrm{mM}$ dithiothreitol (DTT), $1 \mathrm{mM}$ EDTA, $150 \mathrm{mM} \mathrm{NaCl}$ ) overnight at $4^{\circ} \mathrm{C}$, using a Slide-A-Lyzer Dialysis Cassette, 10000 MWCO (Thermo Scientific) and concentrated to $\sim 0.5-1 \mathrm{ml}$, using an Amicon Ultra-15 $50 \mathrm{~K}$ Centrifugal Filter Device. The concentration was determined by Bradford assay (Sigma) using BSA (Thermo Scientific) as the control. Expression of S83L and S83R GyrA was performed identically to expression of the WT GyrA.

DNA gyrase cleavage. DNA gyrase cleavage assays were performed as previously described with minor changes ${ }^{12,37,54}$. Ten micrograms per millilitre supercoiled DNA (pBR322, Inspiralis) was added to buffer (35 mM Tris-HCl pH 7.5, $24 \mathrm{mM}$ $\mathrm{KCl}, 4 \mathrm{mM} \mathrm{MgCl}_{2}, 2 \mathrm{mM}$ DTT, $1.8 \mathrm{mM}$ spermidine, $6.5 \%$ glycerol, $0.1 \mathrm{mg} \mathrm{ml}^{-1}$ albumin) with compound or vehicle. Compound concentrations were $0.01,0.04$, $0.17,0.68,2.7$ and $10.8 \mu \mathrm{M}$, except for DNM, which was $8.9 \mu \mathrm{M}$ for its highest concentration. DNA gyrase was added to a final concentration of $16 \mathrm{nM}$ gyrA and $32 \mathrm{nM}$ gyrA (giving a final concentration of $A_{2} B_{2}$ of $8 \mathrm{nM}$ ) for $25 \mathrm{~min}$ at $30^{\circ} \mathrm{C}$. Linear product was revealed by addition of $0.2 \%$ SDS and $0.1 \mu \mathrm{g} \mathrm{ml}^{-1}$ proteinase $\mathrm{K}$ for $30 \mathrm{~min}$ at $37^{\circ} \mathrm{C}$. DNA loading dye (Thermo Scientific) was added to the samples and they were run on $1 \%$ agarose gels containing $0.5 \mu \mathrm{g} \mathrm{ml}^{-1}$ ethidium bromide. Gels were imaged on a Molecular Imager Gel Doc XR + (Biorad) and bands were quantified using Image $J^{4}$. Per cent of type of DNA was calculated with total DNA in each lane being $100 \%$. For time-course cleavage assays, the same protocol was followed, except that the initial incubation was for varying times $(0,1,3,5,10,15,20,30,60,90,120$ and $180 \mathrm{~min})$ instead of $25 \mathrm{~min}$.

Human topoisomerase decatenation assay. The decatenation assay was performed with the Human Topo II Decatenation Assay Kit (Inspiralis), according to the manufacturer's instructions, with minor modifications. First, a master mix was made containing $2 \mu \mathrm{l}$ of $10 \times$ assay buffer $(500 \mathrm{mM}$ Tris-HCl pH 7.5, $1250 \mathrm{mM}$ $\mathrm{NaCl}, 100 \mathrm{mM} \mathrm{MgCl}_{2}, 50 \mathrm{mM}$ DTT, $1,000 \mu \mathrm{g} \mathrm{ml}^{-1}$ albumin), $0.67 \mu \mathrm{l}$ of $30 \mathrm{mM}$

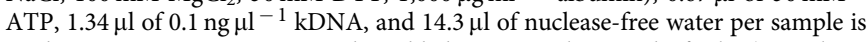
made. DMSO or $30 \times$ compound is added to a $0.5-\mathrm{ml}$ Eppendorf tube $(0.67 \mu \mathrm{l}$ per tube). The master mix is then added to each tube ( $18.3 \mu \mathrm{l}$ per tube). Finally, $1 \mathrm{U}$ of

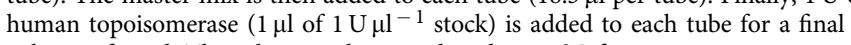
volume of $20 \mu \mathrm{l}$. The tubes are then incubated at $37^{\circ} \mathrm{C}$ for $30 \mathrm{~min}$. Reactions are stopped by the addition of $20 \mu \mathrm{l}$ of 24:1 chloroform:isoamyl alcohol and $20 \mu \mathrm{l}$ of stop dye (40\% sucrose, $1 \mathrm{mM}$ EDTA, $100 \mathrm{mM}$ Tris-HCl pH 7.5, $0.5 \mu \mathrm{g} \mathrm{ml}^{-1}$ bromophenol blue). Samples were run on $1 \%$ agarose gels containing $0.5 \mu \mathrm{g} \mathrm{ml}^{-1}$ ethidium bromide for $1 \mathrm{~h}$ at $110 \mathrm{~V}$ or until the dye front was approximately halfway down the gel. Gels were imaged on a Molecular Imager Gel Doc XR + (Biorad).

Resistant mutant generation. Agar plates $(15 \mathrm{~cm})$ were prepared containing $\mathrm{MH}$ broth and antibacterial compounds at concentrations detailed in the Supplementary Fig. 6. Forty millilitres of an overnight bacterial culture was centrifuged at 3,000 $\times \mathrm{g}$ for $10 \mathrm{~min}$ and resuspended in $0.4 \mathrm{ml}$ of sterile PBS. Plates were inoculated with $100 \mu \mathrm{l}$ of bacteria in PBS by spreading with beads. Inoculated plates were then incubated at $37^{\circ} \mathrm{C}$ for $72 \mathrm{~h}$ and the number of resistant colonies was counted. To determine the number of viable colonies spread onto each plate, dilutions of the overnight culture in sterile PBS were spread onto non-selective $\mathrm{MH}$ agar plates and plates were incubated overnight at $37^{\circ} \mathrm{C}$ before counting colonies.

In-vitro haemolysis assay. Haemolysis assays were performed as previously described ${ }^{55}$. Briefly, assays were performed using human erythrocytes within 3 days of receipt. One millilitre of human blood purchased from Bioreclamation, Inc. (Hicksville, NY) was centrifuged $(10,000 \times g, 2 \mathrm{~min})$. The pellet was washed three times with sterile saline $(0.9 \% \mathrm{NaCl}$ in water) by repeated gentle suspension and centrifugation. The pellet was resuspended in RBC buffer $\left(10 \mathrm{mM} \mathrm{Na}_{2} \mathrm{HPO}_{4}\right.$, $150 \mathrm{mM} \mathrm{NaCl}, 1 \mathrm{mM} \mathrm{MgCl} 2 \mathrm{pH} 7.4$ ). To evaluate haemolytic activity of DNM and derivatives, $1 \mu \mathrm{l}$ either $3.2 \mathrm{mg} \mathrm{ml}^{-1}$ DMSO stock (or the most concentrated stock of the compound available if not soluble at $3.2 \mathrm{mg} \mathrm{ml}^{-1}$ in DMSO) was transferred to $0.5 \mathrm{ml}$ Eppendorf tubes containing $19 \mu \mathrm{l}$ RBC buffer. Negative control tubes contained $1 \mu \mathrm{l}$ DMSO and $19 \mu \mathrm{l}$ RBC buffer, and positive control tubes contained $1 \mu \mathrm{l}$ DMSO and $19 \mu \mathrm{l}$ sterile deionized water. A suspension of washed erythrocytes $(10 \mu \mathrm{l})$ was added to each tubes and samples were incubated at $37^{\circ} \mathrm{C}$ for $2 \mathrm{~h}$. Samples were centrifuged at $10,000 \times g$ for $2 \mathrm{~min}$ and the supernatants from each sample $(25 \mu \mathrm{l})$ were transferred to a clear, sterile 384 -well plate. The absorbance of these supernatants was measured at $540 \mathrm{~nm}$ using a SpectraMaxPlus384 absorbance plate reader (Molecular Devices). Per cent haemolysis of each sample was calculated relative to the average absorbance values measured for positive controls.

Intercalation assay. Intercalation assays were performed as previously described $^{34}$. The ability of DNM-2 to intercalate into DNA was measured by an ethidium bromide displacement assay. Herring Sperm DNA $\left(34 \mu \mathrm{g} \mathrm{ml}^{-1}\right.$ final) was premixed with buffer containing ethidium bromide $(50 \mathrm{mM}$ Tris base, $100 \mathrm{mM}$ $\mathrm{NaCl}, 1 \mathrm{mM}$ EDTA, $5 \mu \mathrm{M} \mathrm{EtBr} \mathrm{pH} \mathrm{7.5).} \mathrm{Ninety-five} \mathrm{microlitres} \mathrm{of} \mathrm{this} \mathrm{solution} \mathrm{was}$ added to a 96 -well plate containing $5 \mu \mathrm{l}$ of DMSO solutions of compounds. In addition to vehicle controls, wells lacking either DNA or EtBr were also used to ensure that these did not have an effect on fluorescence. Doxorubicin was used as a positive control. The reactions were allowed to incubate for $30 \mathrm{~min}$. Fluorescence was then read on a Gemini microplate reader (Molecular Devices, excitation $=545 \mathrm{~nm}$, emission $=595 \mathrm{~nm}$ )

Pharmacokinetic assessment. The animal studies ( $\mathrm{PK}$, in-vivo toxicity and in-vivo efficacy) were carried out in strict accordance with the recommendations in the Guide for the Care and Use of Laboratory Animals of the National Institutes of Health. The protocol was approved by the Institutional Animal Care and Use Committee (IACUC) at the University of Illinois at Urbana-Champaign (Protocol Number: 13406). In these studies, 10- to 12-week-old female C57BL/6 mice purchased from Charles River were used. DNM, DNM-2 and DNM-3 were formulated as slurries at $8.3 \mathrm{mg} \mathrm{ml}^{-1}$ in $25 \%$ Cremophor RH40/water (v/v). Before beginning the pharmacokinetic assessment, mice were first tested for their ability to tolerate the DNM, DNM-2 and DNM-3 at $50 \mathrm{mg} \mathrm{kg}^{-1}$ (p.o.). After establishing that this dose was well tolerated, mice were treated with DNM, DNM-2 or DNM-3 (all $50 \mathrm{mg} \mathrm{kg}^{-1}$ ) via oral gavage, with three mice per time point $(15,30,60,120$, 240 and $480 \mathrm{~min}$ ). At specified time points, mice were killed and blood was collected, centrifuged and the serum was frozen at $-80^{\circ} \mathrm{C}$ until analysis. The proteins in a $50-\mu \mathrm{l}$ aliquot of serum were precipitated by the addition of $50 \mu \mathrm{l}$ of acetonitrile and the sample was centrifuged to remove the proteins. Serum concentrations of DNM, DNM-2 and DNM-3 were determined by HPLC. PK parameters were determined using GraphPad Prism Version 5.00 for Windows.

In-vivo toxicity assessment. The protocol was approved by the IACUC at the University of Illinois at Urbana-Champaign (Protocol Number: 14032). Six-weekold male pathogen-free $\mathrm{BALB} / \mathrm{c}$ mice were purchased from Taconics Biosciences (Albany, NY). All animals were housed in a pathogen-free environment and received sterile food and water. Mice $(n=5)$ were treated once daily for 10 days, with $50 \mathrm{mg} \mathrm{kg}^{-1}$ DNM-2 or vehicle (25\% Cremophor RH $40 / \mathrm{PBS}(\mathrm{v} / \mathrm{v})$ ), by oral gavage. Toxicity was assessed as previously described ${ }^{56}$. Specifically, heparinized whole blood was collected for assessment of total white blood cells, neutrophils, lymphocytes, haematocrit, platelets, creatinine, blood urea, nitrogen, albumin, alanine aminotransferase, alkaline phosphatase and total bilirubin. Mice were euthanized by overdosing with ketamine/xylazine and the heart, lung, kidney, liver, spleen, gastrointestinal tract and the brain were collected for histopathology. Tissue samples were fixed $24 \mathrm{~h}$ in $10 \%$ neutral buffered formalin, processed and paraffin embedded, sectioned ( $5 \mu \mathrm{m}$ thickness) and stained with haematoxylin and eosin. All slides were systematically evaluated by a single board-certified veterinary anatomic pathologist (SL) for evidence of acute or chronic inflammation and toxicity. All lesions were characterized, recorded and scored for severity $($ minimal $=1$, mild $=2$, moderate $=3$, marked $=4$, and severe $=5)$.

In-vivo efficacy. The protocol was approved by the IACUC at the University of Illinois at Urbana-Champaign (Protocol Number: 14032). Six-week-old male pathogen-free $\mathrm{BALB} / \mathrm{c}$ mice were purchased from Harlan Sprague--Dawley (Indianapolis, IN). All animals were housed in a pathogen-free environment and received sterile food and water. For the inoculation, overnight cultures of $S$. aureus clinical isolate NRS3 were diluted 1:100 into fresh tryptic soy broth and grown for $2 \mathrm{~h}$ at $37^{\circ} \mathrm{C}$. Bacteria were washed and resuspended in sterile PBS. The mice were anaesthetized with ketamine and xylazine. The mouse tails were pre-warmed in $45^{\circ} \mathrm{C}$ for $5 \mathrm{~min}$ before $1.2 \times 10^{8}$ colony-forming units of S. aureus in $50 \mu \mathrm{l}$ of PBS were injected into a tail vein using a 29 -gauge needle. This number of bacteria was determined from a series of preliminary studies in which groups of mice were infected with a range of $10^{6}-10^{9}$ colony-forming units of S. aureus. Infected mice (15 mice per group) were then treated once daily for 10 days with $50 \mathrm{mg} \mathrm{kg}^{-1}$ DNM-2, $50 \mathrm{mg} \mathrm{kg}^{-1}$ CIP or vehicle (25\% Cremophor RH 40/PBS (v/v)), by oral gavage. For survival analyses, a Kaplan-Meier Log Rank Survival Test was performed using OriginPro 9 (Northampton, MA) 


\section{References}

1. Hooper, D. C. Fluoroquinolone resistance among Gram-positive cocci. Lancet Infect. Dis. 2, 530-538 (2002).

2. Linder, J. A., Huang, E. S., Steinman, M. A., Gonzales, R. \& Stafford, R. S. Fluoroquinolone prescribing in the United States: 1995 to 2002. Am. J. Med. 118, 259-268 (2005).

3. Hicks, L. A., Taylor, Jr. T. H. \& Hunkler, R. J. U.S. outpatient antibiotic prescribing, 2010. N. Engl. J. Med. 368, 1461-1462 (2013).

4. Redgrave, L. S., Sutton, S. B., Webber, M. A. \& Piddock, L. J. Fluoroquinolone resistance: mechanisms, impact on bacteria, and role in evolutionary success. Trends Microbiol. 22, 438-445 (2014).

5. Chambers, H. F. in Basic and Clinical Pharmacology. (ed Katzung, B. G.) Ch. 46, 763-770 (McGraw-Hill, 2007).

6. Chen, S. H., Chan, N. L. \& Hsieh, T. S. New mechanistic and functional insights into DNA topoisomerases. Annu. Rev. Biochem. 82, 139-170 (2013).

7. Pommier, Y. Drugging topoisomerases: lessons and challenges. ACS Chem. Biol. 8, 82-95 (2013).

8. Gellert, M., Mizuuchi, K., O’Dea, M. H. \& Nash, H. A. DNA gyrase: an enzyme that introduces superhelical turns into DNA. Proc. Natl Acad. Sci. USA 73, 3872-3876 (1976).

9. Jacoby, G. A. Mechanisms of resistance to quinolones. Clin. Infect. Dis. 41(Suppl 2): S120-S126 (2005).

10. Dalhoff, A. Resistance surveillance studies: a multifaceted problem--the fluoroquinolone example. Infection 40, 239-262 (2012).

11. Aldred, K. J. et al. Overcoming target-mediated quinolone resistance in topoisomerase IV by introducing metal-ion-independent drug-enzyme interactions. ACS Chem. Biol. 8, 2660-2668 (2013).

12. Barnard, F. M. \& Maxwell, A. Interaction between DNA gyrase and quinolones: effects of alanine mutations at GyrA subunit residues Ser(83) and Asp(87). Antimicrob. Agents Chemother. 45, 1994-2000 (2001).

13. Kwak, Y. G. et al. Association of norB overexpression and fluoroquinolone resistance in clinical isolates of Staphylococcus aureus from Korea. J. Antimicrob. Chemother. 68, 2766-2772 (2013).

14. Wang, S., Wang, Y., Shen, J., Wu, Y. \& Wu, C. Polymorphic mutation frequencies in clinical isolates of Staphylococcus aureus: the role of weak mutators in the development of fluoroquinolone resistance. FEMS. Microbiol. Lett. 341, 13-17 (2013).

15. Hiramatsu, K. et al. Curing bacteria of antibiotic resistance: reverse antibiotics, a novel class of antibiotics in nature. Int. J. Antimicrob. Agents 39, 478-485 (2012).

16. Baba, K. et al. Prevalence and mechanism of antimicrobial resistance in Staphylococcus aureus isolates from diseased cattle, swine and chickens in Japan. J. Vet. Med. Sci. 74, 561-565 (2012).

17. Costa, S. S. et al. Exploring the contribution of efflux on the resistance to fluoroquinolones in clinical isolates of Staphylococcus aureus. BMC Microbiol. 11, 241 (2011).

18. Sanfilippo, C. M., Hesje, C. K., Haas, W. \& Morris, T. W. Topoisomerase mutations that are associated with high-level resistance to earlier fluoroquinolones in Staphylococcus aureus have less effect on the antibacterial activity of besifloxacin. Chemotherapy 57, 363-371 (2011).

19. Aligholi, M. et al. Phenotypic and genotypic evaluation of fluoroquinolone resistance in clinical isolates of Staphylococcus aureus in Tehran. Med. Sci. Monit. 17, PH71-PH74 (2011).

20. Yoon, E. J. et al. Extended spectrum of quinolone resistance, even to a potential latter third-generation agent, as a result of a minimum of two GrlA and two GyrA alterations in quinolone-resistant Staphylococcus aureus. Chemotherapy 56, 153-157 (2010).

21. Coskun-Ari, F. F. \& Bosgelmez-Tinaz, G. grlA and gyrA mutations and antimicrobial susceptibility in clinical isolates of ciprofloxacin- methicillinresistant Staphylococcus aureus. Eur. J. Med. Res. 13, 366-370 (2008).

22. Sadowy, E. et al. High abundance and diversity of antimicrobial resistance determinants among early vancomycin-resistant Enterococcus faecium in Poland. Eur. J. Clin. Microbiol. Infect. Dis. 32, 1193-1203 (2013).

23. Werner, G. et al. High-level ciprofloxacin resistance among hospital-adapted Enterococcus faecium (CC17). Int. J. Antimicrob. Agents 35, 119-125 (2010).

24. Grohs, P., Houssaye, S., Aubert, A., Gutmann, L. \& Varon, E. In vitro activities of garenoxacin (BMS-284756) against Streptococcus pneumoniae, viridans group streptococci, and Enterococcus faecalis compared to those of six other quinolones. Antimicrob. Agents Chemother. 47, 3542-3547 (2003).

25. Tremblay, C. L., Charlebois, A., Masson, L. \& Archambault, M. Characterization of hospital-associated lineages of ampicillin-resistant Enterococcus faecium from clinical cases in dogs and humans. Front. Microbiol. 4, 245 (2013).

26. Rathnayake, I. U., Hargreaves, M. \& Huygens, F. Antibiotic resistance and virulence traits in clinical and environmental Enterococcus faecalis and Enterococcus faecium isolates. Syst. Appl. Microbiol. 35, 326-333 (2012).

27. Brock, T. D. \& Sokolski, W. T. Biological studies on the antibiotic, nybomycin. Antibiot. Chemother. (Northfield Ill) 8, 631-636 (1958).
28. Strelitz, F., Flon, H. \& Asheshov, I. N. Nybomycin, a new antibiotic with antiphage and antibacterial properties. Proc. Natl Acad. Sci. USA 41, 620-624 (1955).

29. Rinehart, K. L. \& Renfroe, H. B. The structure of nybomycin. J. Am. Chem. Soc 83, 3729-3731 (1961).

30. Naganawa, H., Wakashiro, T., Yagi, A., Kondo, S. \& Takita, T. Deoxynybomycin from a Streptomyces. J. Antibiot. 23, 365-378 (1970).

31. Adelmann, S., Baldhoff, T., Koepcke, B. \& Schembecker, G. Selection of operating parameters on the basis of hydrodynamics in centrifugal partition chromatography for the purification of nybomycin derivatives. J. Chromatogr A. 1274, 54-64 (2013)

32. Forbis, R. M. \& Rinehart, K. L. Nybomycin.4. Total synthesis of deoxynybomycin. J. Am. Chem. Soc. 92, 6995-699 (1970).

33. Forbis, R. M. \& Rinehart, K. L. Nybomycin.7. Preparative routes to nybomycin and deoxynybomycin. J. Am. Chem. Soc. 95, 5003-5013 (1973)

34. Bair, J. S., Palchaudhuri, R. \& Hergenrother, P. J. Chemistry and biology of deoxynyboquinone, a potent inducer of cancer cell death. J. Am. Chem. Soc. 132, 5469-5478 (2010).

35. Angibaud, P. et al. 5-imidazolyl-quinolinones, -quinazolinones and -benzoazepinones as farnesyltransferase inhibitors. Bioorg. Med. Chem. Lett. 13, 1543-1547 (2003).

36. Parkinson, E. I., Bair, J. S., Cismesia, M. \& Hergenrother, P. J. Efficient NQO1 substrates are potent and selective anticancer agents. ACS Chem. Biol. 8, 2173-2183 (2013).

37. Kampranis, S. C. \& Maxwell, A. The DNA gyrase-quinolone complex. ATP hydrolysis and the mechanism of DNA cleavage. J. Biol. Chem. 273, 22615-22626 (1998).

38. Bax, B. D. et al. Type IIA topoisomerase inhibition by a new class of antibacterial agents. Nature 466, 935-940, 2010).

39. Ferrero, L., Cameron, B. \& Crouzet, J. Analysis of gyrA and grlA mutations in stepwise-selected ciprofloxacin-resistant mutants of Staphylococcus aureus. Antimicrob. Agents Chemother. 39, 1554-1558 (1995).

40. Hori, S., Ohshita, Y., Utsui, Y. \& Hiramatsu, K. Sequential acquisition of norfloxacin and ofloxacin resistance by methicillin-resistant and -susceptible Staphylococcus aureus. Antimicrob. Agents Chemother. 37, 2278-2284 (1993).

41. Egawa, K. et al. Deoxynybomycin is a selective anti-tumor agent inducing apoptosis and inhibiting topoisomerase I. Biol. Pharm. Bull. 23, 1036-1040 (2000).

42. Li, S. et al. Pseudonocardians A-C, new diazaanthraquinone derivatives from a deap-sea actinomycete Pseudonocardia sp. SCSIO 01299. Mar. Drugs 9, 1428-1439 (2011).

43. Price, L. B. et al. In vitro selection and characterization of Bacillus anthracis mutants with high-level resistance to ciprofloxacin. Antimicrob. Agents Chemother. 47, 2362-2365 (2003).

44. Vila, J. et al. Association between double mutation in gyrA gene of ciprofloxacin-resistant clinical isolates of Escherichia coli and MICs. Antimicrob. Agents Chemother. 38, 2477-2479 (1994).

45. Vila, J., Ruiz, J., Goni, P., Marcos, A. \& Jimenez de Anta, T. Mutation in the gyrA gene of quinolone-resistant clinical isolates of Acinetobacter baumannii. Antimicrob. Agents Chemother. 39, 1201-1203 (1995).

46. Vernel-Pauillac, F., Hogan, T. R., Tapsall, J. W. \& Goarant, C. Quinolone resistance in Neisseria gonorrhoeae: rapid genotyping of quinolone resistancedetermining regions in gyrA and parC genes by melting curve analysis predicts susceptibility. Antimicrob. Agents Chemother. 53, 1264-1267 (2009).

47. Deguchi, T. et al. Alterations in the GyrA subunit of DNA gyrase and the ParC subunit of topoisomerase IV in quinolone-resistant clinical isolates of Klebsiella pneumoniae. Antimicrob. Agents Chemother. 41, 699-701 (1997).

48. Bast, D. J. et al. Fluoroquinolone resistance in clinical isolates of Streptococcus pneumoniae: contributions of type II topoisomerase mutations and efflux to levels of resistance. Antimicrob. Agents Chemother. 44, 3049-3054 (2000).

49. Talbot, G. H. et al. Bad bugs need drugs: an update on the development pipeline from the Antimicrobial Availability Task Force of the Infectious Diseases Society of America. Clin. Infect. Dis. 42, 657-668 (2006).

50. Moritz, E. M. \& Hergenrother, P. J. Toxin-antitoxin systems are ubiquitous and plasmid-encoded in vancomycin-resistant enterococci. Proc. Natl Acad. Sci. USA 104, 311-316 (2007).

51. Bratu, S., Landman, D., Martin, D. A., Georgescu, C. \& Quale, J. Correlation of antimicrobial resistance with beta-lactamases, the OmpA-like porin, and efflux pumps in clinical isolates of Acinetobacter baumannii endemic to New York City. Antimicrob. Agents Chemother. 52, 2999-3005 (2008).

52. Wikler, M. A. et al. Methods for Dilution Antimicrobial Susceptibility Tests for Bacteria That Grow Aerobically; Approved Standard 7 edn, Vol. 26Clinical and Laboratory Standards Institute, 2006).

53. Tran, J. H., Jacoby, G. A. \& Hooper, D. C. Interaction of the plasmid-encoded quinolone resistance protein Qnr with Escherichia coli DNA gyrase. Antimicrob. Agents Chemother. 49, 118-125 (2005).

54. Fisher, L. M. \& Pan, X. S. Methods to assay inhibitors of DNA gyrase and topoisomerase IV activities. Methods Mol. Med. 142, 11-23 (2008). 
55. Eibergen, N. R., Im, I., Patel, N. Y. \& Hergenrother, P. J. Identification of a novel protein synthesis inhibitor active against Gram-positive bacteria. Chembiochem 13, 490 (2012).

56. Botham, R. C. et al. Dual small-molecule targeting of procaspase-3 dramatically enhances zymogen activation and anticancer activity. J. Am. Chem. Soc. 136, 1312-1319 (2014)

\section{Acknowledgements}

We thank Cubist Pharmaceuticals for generating the MRSA clinical isolate data (Fig. 2a) and providing DNA from those isolates. We thank Professor David C. Hooper for providing the plasmids pTRC-HisA-GyrA and pTRC-HisA-GyrB. We thank Professor Tim Fan, Professor Levent Dirikolu and Andrew Lee for technical assistance. This work was supported by the University of Illinois (P.J.H.) and the National Institutes of Health (NIH) Grant R01HL090699 (G.W.L.). E.I.P. is a National Science Foundation pre-doctoral fellow and an ACS Medicinal Chemistry pre-doctoral fellow. B.A.N. is a National Defense Science and Engineering pre-doctoral fellow.

\section{Author contributions}

P.J.H., E.I.P. and J.S.B. conceived the study. J.S.B. designed the synthesis of DNM and all derivatives, except compound 5. E.I.P. and E.H.S. designed the synthesis of derivative 5. E.I.P., B.A.N., H.I.K. and E.H.S. executed the synthesis of the compounds used in this study. E.I.P. designed and executed the biological experiments including MIC determinations, sequencing of the QRDR of clinical isolates, in vitro analysis of DNA gyrase inhibition and development of resistant mutants. H.Y.L. performed the pharmacokinetic analysis. G.W.L. designed and executed the mouse model of infection S.L. performed clinical pathology and histopathology toxicity evaluations. P.J.H. and E.I.P. analysed the data and wrote the manuscript, with the assistance of J.S.B., B.A.N., H.Y.L. S.L., and G.W.L.

\section{Additional information}

Supplementary Information accompanies this paper at http://www.nature.com/ naturecommunications

Competing financial interests: The University of Illinois has filed patents on DNM and its derivatives, with E.I.P., J.S.B and P.J.H. listed as inventors. All other author declare no competing financial interests.

Reprints and permission information is available online at http://npg.nature.com/ reprintsandpermissions/

How to cite this article: Parkinson, E. I. et al. Deoxynybomycins inhibit mutant DNA gyrase and rescue mice infected with fluoroquinolone-resistant bacteria. Nat. Commun. 6:6947 doi: 10.1038/ncomms7947 (2015).

\section{(c) (i)}

This work is licensed under a Creative Commons Attribution 4.0 International License. The images or other third party material in this article are included in the article's Creative Commons license, unless indicated otherwise in the credit line; if the material is not included under the Creative Commons license, users will need to obtain permission from the license holder to reproduce the material To view a copy of this license, visit http://creativecommons.org/licenses/by/4.0/ 